\title{
Socrates in Earpods? The iPodification of Education
}

\author{
Tara Brabazon
}

My dreams are filled with thoughts of revenge. In a rescripting of Bill and Ted's Excellent Adventure, I have dreams of Socrates_-pronounced So-crates for the purposes of the film-returning once more. This time, he is not visiting a proto-Pretty in Pink high school of John Hughes's imagination. Instead, the stroppy old philosopher visits our marketized, corporatized, branded, spruiked and spun 'universities.' He wanders around the car parks, kebab stands, automatic teller machines and computer terminals. But instead of asking the profound questions about the nature of truth, beauty and self, So-crates marches up to the plush offices of the chancellery building and demands to see the Vice Chancellor. Upon entry into the suite with panoramic views, So-crates grabs the V.C. by the throat and with a Steve Irwin guttural Oz-tray-lee-an accent, splutters a far more direct and disturbing question than from his days in Athens: "what the bloody hell is going on here?"

Clearly, I have a rich and varied fantasy life. If I did not, then the concrete, copyright and conflicts in universities would get me down. But we do need a Socrates to ask the difficult questions that no longer have space or support to demand an answer. This article for Fast Capitalism has a goal: to probe the role and function of digitized sound in teaching and learning. The policies, agendas and assumptions about i-lectures and the ipodification of teaching spaces need to be assessed.

There is a direct trigger for my concern, and not surprisingly it involves advertising campaigns for universities. Before Christmas 2005, Murdoch University in Perth inserted a large, glossy pamphlet into the national newspaper, The Australian. On the same page that featured a story on "Australia's top teaching rankings," was a crashing headline: "mp3 technology: a new wave in learning."

\begin{abstract}
At some high schools, MP3 players are taboo. Next year at Murdoch they will be encouraged-it is all part of an everwidening variety of study options for students. The ubiquitous MP3 will at last give students total flexibility for when and where they listen to the lectures they are unable to attend-students will simply download lectures to their Ipod and listen at their leisure, anywhere!
\end{abstract}

The increased flexibility builds on 'ilecture' a hugely successful innovation introduced last year, which broadcasts lectures over the Internet. The new MP3 technology demonstrates a new leap in flexible learning, as students will no longer have to be anchored to a computer. (“MP3 technology":4)

This brochure was then retexted on a promotional website that once more affirmed the ipod, with quotations from the Pro-Vice Chancellor (Academic). Professor Jan Thomas is described as "a former student of Murdoch's Veterinary School who went on to teach at the University. Ten years ago she realized university teaching practices needed to be updated." (http://www.ccpr.murdoch.edu.au/opportunity/mp3.html) The rationale for these 'improvements' was not determined by changes to pedagogy, literacy theory, international trends in curriculum development, library studies or information management. Instead, she states,

more and more of our students are juggling their studies with jobs and family commitments, which make attendance at all lectures increasingly difficult. (http://www.ccpr.murdoch.edu.au/opportunity/mp3.html) 
University students have always worked, and students have always upheld family commitments, unless they were raised by wolves. The Pro-Vice Chancellor is not only riding the ideological surf that rolls progress, pedagogy and technology into a tidal wave of educational change, but is justifying-or excusing - nonattendance at lectures. For the academic leader of a university to offer this rationalization is remarkable. While she does still value "contact between staff and students," she also concedes—even in her own advertisement—-that "we will continue to provide face-to-face contact with lecturers for most of our courses." (emphasis added http://www.ccpr.murdoch.edu. $\mathrm{au} /$ opportunity/mp3.html) At the same time that the Pro Vice Chancellor was making these statements, other universities around the world, including Oxford, are requiring students to sign contracts committing to lecture and tutorial attendance. In February 2006, The West Australian newspaper reported that a range of universities have policies to ensure students fulfill their responsibilities within a teaching program. At the conclusion of the article, the journalist reported that "Murdoch and the University of WA do not require students to sign attendance contracts and have no plans to start" (Rasdien 2006:58). Both these institutions have based their academic and intellectual futures on flexible learning, i-lectures and ipods. Confirming—and perhaps enforcing—attendance on campus works against their present strategies.

These wild West(ern Australian) Universities are not alone in masking the 'change management' of academics, teaching and technology with discussion of flexibility and choice. For example, Vice Chancellor Diana Green of Sheffield Hallam University revealed the impact of education's ipodification.

More and more students either work for cash or do volunteer work in the community and, compared with 20 years ago, students are forced to manage their time better. Students also have much less structured time, with more learning done via the internet. I think there is more pressure on them because they are still expected to do just as well, even though they are learning many of the subjects by themselves. (Green in Borland 2005:5)

When I read her statement—and kept returning to her words assuming I had missed a phrase—I realized it was time to unpick the assumptions of flexible learning, particularly for the most junior of our undergraduates. That a Vice Chancellor would doom a generation of students to learn 'by themselves' in full conscience and awareness, justifying this pedagogy by the affirmation that "learning [is] done via the internet," confirms why this article for Fast Capitalism was written. Every technological application, hardware invention or software innovation has its marketers and public relations consultants employed to sell its value. Indeed, these cited statements were derived from academic managers speaking to journalists, not at a scholarly conference or written as part of a refereed article. While selling flexibility and change, there are few such celebrations and advertisements for the small victories in reading, writing and thinking. Good teachers-who are not satisfied with students learning 'by themselves' or being permitted/ encouraged/facilitated to miss lectures-must transgress and transform this digital diatribe to stretch ourselves and aim for higher standards. Learning is not 'done' via the internet. Learning is not 'done' through ipod earphones. Learning is not 'done' in a classroom. All learning is conducted in a context that constructs a scholarly and structured relationship between data, information and knowledge. It is the relationship between teachers and students that configures a learning environment. No one learns anything 'by themselves' or in isolation. The best scholars value the intellectuals that precede them, and demonstrate this scholarly allegiance and inheritance through research and dense footnotage. We as teachers should not accept the structures imposed by human resource managers and educational administrators who attempt to place a lifetime of learning and expertise into a weekly spreadsheet. The replacement of educational revelation with technological competency is a product of the managerial transformation of universities. In such an environment the sounds of education are even more important.

Socrates was not a believer in writing. He thought it created a lazy intellect and poor memory. It was left to Plato to write (about) Socrates and Aristotle to link thinking with reading. Socrates affirmed the specialness of oral and aural culture: he did not want thinkers to undermine its value and potential. Sound is a medium of communication that shadows the truths of our era. Its message is difficult to determine with precision, but facilitates the passion of the best popular music or the intense reflection and concentration of riveting public speeches. Sound slows our interpretation of words and ideas, heightens the awareness of our environment and encourages quiet interiority. Listening to music delves into our personal stories of loss, love and hope. Hearing waves crash onto a beach is simultaneously rhythmic, soothing and gothic. Laying in bed, just about to cross over into the twilight of sleep, we hear our breath and the flooded silence of a darkened house.

Follow me on this journey. At the conclusion of this paragraph, close your eyes. Wherever you are-in the easy 
chair at home, in a library or sipping a long black coffee in an office, I want you to eliminate your visual engagement with the world — just temporarily_ and become aware of the sonic layering in the environment. For one minute, be conscious of the sounds of undulating breath, and how it punctuates the soundscape. Close your eyes now.

Upon reopening access to the visual realm, there is a realization of the intricate complexity of sound about which we are frequently unaware. As the starkness of light and printed words are darkened, the pools of sound become more deep and resonant. The layering of sonic media, from the humming of a computer to the gentle sigh of our breath, encourages more dense and delicate interpretations of the world. Our ears arch out into space to position the body in distinct and new ways. Hearing sound-and processing that experience-activates intricate aural literacies.

Sound punctuates buildings, workplaces, leisure complexes and family life. It bleeds through the media-from film soundtracks to streamed university lectures. To map and mobilize sound requires concise interpretation of the critical approaches that allow us to understand its role in creating space, place and identity. When the visual bias of Western Culture is questioned, we hear sounds (and ideas) that have been ignored. As Paul Duncum (2004) has confirmed, "there are no exclusively visual sites" (p. 252). While popular music is an important part of this aural landscape, there are many contexts and modes of sound. Education rarely manages to utilize this sophistication. Formal educational structures, through primary and high school, are geared to develop the literacies in managing print. Monitoring and moderating the layering of aurality adds art and craft to education. Too often, we as teachers cheapen soundscapes with monotone verbal deliveries in lectures, interjected with stammering and confusion, and do not open our ears to the myriad other rhythms, melodies and textures in the sonic palette. Not surprisingly, digitization has only increased this tendency. I-lecture rollout is a case study of how the range of sonic media and the significance of sonic literacies is being cheapened and destroyed by the fast Fordism of education. The desire for standardization rather than standards, and compliance rather than complexity, needs the phrase 'flexible learning' to displace and hide the value of a disciplined, rigorous, motivated and — at times — ruthless commitment to activate learning.

\section{An I-diots Guide to I-lectures}

Lectures have taken a battering in the last few years. One of the oldest modes of teaching, lecturing is criticized because, as Peter Stearns (1996) suggested, "it establishes a hierarchy of authority between the lecturer and students and because it enjoins a rather passive learning mode on the audience" (p. 97). There are more positive interpretations of lecturing, particularly in establishing modes of intellectual leadership. Lectures are multi-modal formations, using sound, vision, gestures, and often scent and touch. As a space where people gather to think about complex ideas, the lecture has pivotal symbolic importance. Also, the 'passivity' of lectures is debatable.

Bad lecturers generate bad lectures. The best of lectures require research, intense preparation, mobilization of diverse media and rehearsal. We have all seen incompetent, lazy or nervous scholars write a few headings on the back of a cigarette packet and then walk into the auditorium. They should not be allowed to teach, as they bring our universities into disrepute. The best of lectures are informative, entertaining, persuasive and stimulating. Generally, each lecture I write takes about three weeks to gather the materials. Then they take three days to write from these notes, and five days to prepare the media and presentation. The research required for a good one hour lecture is immense. For the students, lectures develop skills in understanding and interpreting oral sources and evaluating the hierarchy of important information. The rest of our lives do not have an attached touchpad or mouse to scroll back to important ideas that we may have missed. Lectures layer ideas and media.

Technologies in education have three general functions: to present learning materials, to permit an interaction between learner and text, or to facilitate communication between learners and teachers. Precise and different educational strategies are required to enable each of these functions. These choices must be related to the aims of teaching and learning, not the limits of the technology. In this way, precise criteria are established for determining the effectiveness of a particular platform. It also provides a method to assess if change in educational practices and infrastructure is motivated by cost savings or a commitment to improving the learning for students. There are distinctions between technologies for teaching and for operational purposes. 
From: Rita

Sent: Tuesday, 2 August 2005 3:57 PM

To: Tara Brabazon

Subject: iLecture for COM102?

Hello Tara,

My name is Rita ${ }^{* * * * *}$ and im currently enrolled in COM102.. However, i have a timetable clash between this lecture and another and I am only able to alternate which lecture I go to every week. I was just wondering if the notes of the COM102 lecture will be available on WebCT or the lecture on iLecture? I'm trying to figure out if I am able to stay in both units. :)

Thanks for your time,

Rita

In this case, the point of i-lectures is for convenience. It is not linked with Rita's teaching and learning experience. The timetable clash would be easily solved if she enrolled in the distance or correspondence version of either of these 'clashing' units. Students have always had timetable clashes. They have not always had i-lectures.

For an institution, computers increase efficiency. Simply because email improves —or at least speeds up-the distribution of minutes from a meeting does not mean that it facilitates educational communication between the scholar and student. The language of instruction is different from the language of administration. Technologies for teaching are determined by and through the student's home environment and must be low cost. The audio-visual media are remarkably important to teaching and learning moments, but must be judiciously chosen. No technological platform — even a convergent one-intrinsically makes learning student centred. There are many methods to enable interaction between staff and students. For example, I teach sport and grant it a week of focus in several courses for creative industries, cultural and media studies. A mixed media presentation makes it profoundly successful. Analogue video was used in the lecture and tutorial. A song commenced the lecture-from the digital platform of a compact disc_-but what I (and students) remember from the week are the soccer balls. Throughout the lecture and tutorials, several soccer balls move their way around the room. It adds a physicality and corporeality to the educational experience. Particularly for a group of young men and women in the course, they enjoy the physical movement of touching objects of sport while thinking about the industry and experience of sport. The digital streaming of the audio from this lecture could not capture the bodies and their physicality through the teaching sessions. Similarly, the fabrics used to teach fashion, the scents and smells deployed to explore semiotics and the dancing integral to the understanding of popular music are inappropriate to the digital compliance and standardization of webcast lectures.

Putting 'materials' online has been part of strategy to cut costs, not to 'freshen' teaching and learning. It also encourages bad_-or at least strange-behavior:

From: Yuanetta

Sent: Thursday, 4 August 2005 6:04 PM

To: Tara Brabazon

Subject: Re: lecture notes

Hi Tara, just wanted to know if you post any notes on line from the lectures? I assumed you would so I made no attempt to write anything down from the previous lectures, so I'm having a bit of a panic, now that I can't find anything on the web.

If you don't, could I have access to the overheads you used so that I could make some notes, please? I'll come to your office at a time that's convenient for you.

Thank you

Yuanetta

I was wondering in the first two lectures why some students were sitting in the lecture theater with no paper, pen or bag, and staring at me. Why would first years students 'assume' anything about teaching and learning, particularly in the first few weeks of a university course? The notion that she expected notes would be available online means that technological platforms have become a replacement—a crutch_for learning. I do not make PowerPoint slides or notes available online because I do not want to read my words bounced back to me in assignments. In 'encouraging' independent thought and analysis, not their capacity to simply retext or cut and paste my ideas, there is no safety 
net for students, except attending the lectures and tutorials and completing the course reading. The reason why my courses have low failure rates and many scholars go on to postgraduate study is no accident. I remove their choices - rather than encourage flexible learning. They do not have the choice to fail. They do not have the choice to be lazy. They do not have the choice to ignore the opportunities for thought, dialogue and debate that education provides. My courses teach a meta-lesson. Choices must be earned. First year students in particular need a structure for education. There is a need to learn how to learn, through overt discussions of their responsibilities.

I have always taught in this way. I have spent much of my life reading and working with cultural and critical literacy theory, so I know how to construct an effective curriculum for first years. But I was surprised why 2005 was so distinctive and different from earlier years, with students making odd choices about their learning, like deciding not to take notes during a lecture. I wondered why students had simply not read the required readings, and why there was desperation to download PowerPoint slides. There was only one difference between the teaching methods deployed by the university in 2004 and 2005. The arrival of i-lectures triggered poor decision making in first year students. They stopped completing course readings because the only 'reading' they believe was necessary was derived from PowerPoint slides and listening to an i-lecture from a session they missed. Attendance was not required because the audio delivery of the session is available, to which they may or may not listen. When I removed the 'flexibility' of not attending class and required them to read for their assignments, their assumptions shifted. The key with first year students is to reduce their learning choices, demonstrate the value of intellectual discipline, the necessity to complete wide-ranging reading, and to value the community integral to the building of scholarship.

There is a reason why students have a network of teaching and learning resources, including lectures, tutorials and required readings, rather than simply an i-lecture and PowerPoint slides. Together-analogue and digital, sound, vision and corporeality-they summon a textured landscape of scholarship. After students complete course reading, the lectures offers an interpretation of this reading and the tutorial allows students to independently dialogue with their peers, connecting their research to the lecturer's interpretation and the others in the group. It is a matrix of scholarship. Overheads and PowerPoint slides are not 'required reading.' They are a medium of interpretation, a skeleton of a lecture. Students like Yuanetta need to calm themselves and reassess their priorities. The issue for teachers to address is not student flexibility, but motivation.

Thinking about this relationship between teachers, students and curriculum is controversial. Inserting technology into that equation adds greater intensity. Obviously technology has always been part of education. But there are consequences for using particular platforms, hardware and software to make education location independent, a digispace of i-lectures, ipods and PowerPoint slides. Whitehead (1932) argued that in "teaching you will come to grief as soon as you forget that your students have bodies" (p. 78). These words were written in 1932. While much has changed in the subsequent seventy five years, the creation of teaching moments, learning outcomes and social change necessitates a dense, incisive and humble tether to this past. It is sound, voice, rhythm, syncopation, melody, harmony and corporeality that have been the great casualties of education.

\section{| Hearing the Difference}

In a lecture theater and tutorial room, our words are punctuated by bodies and gestures, appended by a diversity of sources including overhead transparencies or PowerPoint slides, moving and still images, music, rhythms, objects, scents and fabrics. At its best, teaching spaces activate all the senses. To remove this sensory complexity and focus on only sound and aural literacies necessitates a high level of pedagogic expertise and experience in sonic media. Norquay (1987) described this process and acknowledged that "writing for talk is different from the writing you do for print" (p. 1). Greater attention is placed on signposting the structure of the presentation, providing overt indicators that allow the listener to follow the development of an argument.

There is also more attention to voice, pace, pauses and intonation. It is a skill to make words spark off the page and appear as if they are not being read. A range of verbal techniques are necessary to compensate for a lack of body language. The aim is to encourage vocal variety and dynamism through rate, pace, volume, pitch, inflection and pause. Further, the use of short sentences for aural delivery, to forge a direct link between subject and predicate, is an imperative. These competencies are different from the characteristics of the archetypical bad lecturer, with a few comments prompted by headings on PowerPoint slides. This mode of 'preparation' encourages rambling ideas and sentences that do not end. Actually, good audio-only presentations are highly scripted, with each word crafted 
and selected. Vocal training is also extremely important. A recorded voice is distinct from the vocal sounds we hear in daily life. Emotion and energy must be injected into the voice, to compensate for the lack of body language and props.

There is an explanation for this low grade sonic scholarship and the cheapening of sound in education. Lecturing is extremely difficult. It is not a performance. It is a very precise form of public speaking. The intensity of concentration is different from any other activity in life. No other event requires that level of preparation and focus. It is not an efficient use of time, but it is an important deployment of expertise. The mixed mode delivery-moving between print to vision, music to scents, fabric to a soccer ball-is incredibly stressful. After an hour, my clothes are saturated, and much to my embarrassment, I continue to sweat through the following two hour tutorial. While I focus on pulling my voice down to a lower register and slowing the delivery, there are myriad other teaching variables I also have to remember while watching student faces for mis/comprehension. Therefore, the delivery of teaching materials for the voice and ear alone requires a different sort of focus to the mixed modal lecture venue. The point is clear: time must be spent developing media resources for sonic media. Streaming a lecture — cutting the voice away from the body - is not only semiotically painful and inappropriate but creates poor quality educational resources.

Good lecturers have different skills to good broadcasters. Through professional development and training, teachers may develop sonic awareness and pedagogically-appropriate delivery. But good materials for the ear rarely emerge from a lecture theater. Lecturing is a different process from producing audio-only programming. Part of the ease with which lectures have been procured for audio streaming on the World Wide Web is a result of a misunderstanding of the specificity of the lecture as a venue for education. Jonathan Ross and Robert Schultz (2004) for example, attacked the lecture forum in their desire to celebrate the 'revolutionary' and 'transformational' nature of the internet for education.

Unfortunately, however, the lecture format-a technique of covering content that is preferred by students with sequential, auditory processing abilities only—continues to dominate as a preferred form of teaching in many college classrooms. (P.

There are flaws in this argument. Firstly, the most provisional lesson in semiotics teaches us that meaning is determined via the relationship between form and content, signifier and signified. There is no such entity as 'content' that exists without being shaped by form or media. Secondly, and most importantly, very few lecturers use only aurality. If they are present in the auditorium and brought their body along for the lecture, then there must be a visual component. To rewrite Helene Cixous, we speak the body. Our body must be heard.

There is a systematic discrediting of lectures as a public space for a community of scholars to come together to share ideas. Even human resources departments at universities are reducing the economic value of a lecture as part of an academic's palette of responsibilities. As an example, I am using the workload figures from my School and University for 2006. Academics on Teaching and Research Contracts spend 40\% of their time teaching, 40\% of their time researching and $20 \%$ on administration and community service. In 2006, my School constructed a figure of 760 points as representing a fulltime teaching load. It is a changeable number, but how academics reach that figure is significant. The following table presents the financial 'value' for a lecture within this scheme. The data is derived from the three levels of seniority in the Australian university system.

The only assumption I have made in this calculation is limiting the time of lecture preparation to four hours per week, with two hours to set up, present the session and answer queries at the end. That is a very conservative level of preparation. There has never been one lecture in my professional life that has taken as little as four hours to construct. However the resultant hourly 'rate' of a lecture's worth to the university is significant to note. The social and pedagogical 'value' of a lecture is represented in a telling fashion by its economic 'value.' It is no surprise that such a minor part of the university's work/load would be disrespected academically by shunting them online, on ipods, or removing them altogether from teaching and learning. The question of intellectual property rights and the 'value' of the content in lectures will be addressed later in this article, but for the moment we can understand why these sessions are moved around platforms so arbitrarily. There is an administrative and managerial miscomprehension of educational value.

Neither putting lectures online or on an analogue audio cassette was an effective use of these platforms. There are more effective methods to actualize the potential of sound, including the writing of specific material that works for the ear, undertaking professional training in the potential of the voice and recording the material with precision. This carefully prepared material opens out effective learning through the senses. Such time-consuming-but important- 
strategies create a media-rich environment. These 'sonic sessions' as I call them are distinct from a lecture session. They are shorter in duration, and also far more reflexive in terms of their form and content relationship. Sound encourages reflection, not content-heavy data presentation. Therefore, I generally take one or two important topics in the week's teaching, offer an interpretation and a series of questions to consider, and conclude the sonic session. For example, here are three short extracts from the fourteen sonic sessions for my course Creative Industries.

\section{Teaching loads, comparisons and calculations 2006}

\begin{tabular}{|c|c|c|c|c|c|c|c|c|c|}
\hline Details & & $\begin{array}{l}\text { B Level } \\
\text { Lecturer }\end{array}$ & & & $\begin{array}{c}\text { Senior } \\
\text { Lecturer }\end{array}$ & & & $\begin{array}{c}\text { Associate } \\
\text { Prof }\end{array}$ & \\
\hline \multirow[t]{3}{*}{$\begin{array}{l}\text { Base Salary } \\
\text { as of January } \\
2006\end{array}$} & & $\$ 66,168$ & & & $\$ 79,705$ & & & $\$ 96,247$ & \\
\hline & Teaching & Research & Admin & Teaching & Research & Admin & Teaching & Research & Admin \\
\hline & $40 \%$ & $40 \%$ & $20 \%$ & $40 \%$ & $40 \%$ & $20 \%$ & $40 \%$ & $40 \%$ & $20 \%$ \\
\hline $\begin{array}{l}\text { Proportion of } \\
\text { Salary }\end{array}$ & $\$ 26,467$ & $\$ 26,467$ & $\$ 13,234$ & $\$ 31,234$ & $\$ 31,234$ & $\$ 15,941$ & $\$ 38,499$ & $\$ 38,499$ & $\$ 19,250$ \\
\hline $\begin{array}{l}\text { \# Salary } \\
\text { applicable to } \\
\text { teaching }\end{array}$ & $\$ 26,467$ & & & $\$ 31,234$ & & & $\$ 38,499$ & & \\
\hline $\begin{array}{l}\text { Total } \\
\text { teaching in } \\
\text { workload } \\
\text { formula }\end{array}$ & 760 pts & & & 760 pts & & & 760 pts & & \\
\hline $\begin{array}{l}\text { Value in } \$ \\
\text { terms of one } \\
\text { w/load point }\end{array}$ & $\$ 34.82$ & & & $\$ 41.10$ & & & $\$ 50.66$ & & \\
\hline $\begin{array}{l}1 \text { hour lecture } \\
(2 \mathrm{pts}) \times 13 \\
\text { weeks of } \\
\text { semester }\end{array}$ & 26 points & & & 26 points & & & 26 points & & \\
\hline $\begin{array}{l}\text { Total } \\
\text { payment to } \\
\text { lecturer for } 13 \\
\text { lectures }\end{array}$ & $\$ 905.32$ & & & $\$ 1,068.60$ & & & $\$ 1,317.16$ & & \\
\hline $\begin{array}{l}\text { Lecture } \\
\text { preparation } \\
\text { ( } 4 \text { hrs per } \\
\text { week, plus } 2 \\
\text { hrs set up and } \\
\text { presentation } \\
\text { (6hrs x } 13 \\
\text { weeks) }\end{array}$ & $78 \mathrm{hrs}$ & & & $78 \mathrm{hrs}$ & & & $78 \mathrm{hrs}$ & & \\
\hline $\begin{array}{l}\text { Hourly rate } \\
\text { for lectures }\end{array}$ & $\$ 11.60$ & & & $\$ 13.70$ & & & $\$ 16.88$ & & \\
\hline
\end{tabular}

This type of material encourages reflection and is intentionally distinct from lectures. Instead of developing this digital mode of teaching and learning, the imperative of i-lectures is to allow students who miss sessions to further disrespect the educational process and 'make up' for their poor attendance. It is also changing student's expectations of higher education. For example, the Ipswich campus of the University of Queensland was set up with the goal of flexible, wireless delivery of content. The consequences were enormous.

While there is obvious preference for on-line learning at the Ipswich campus, the initial promotion of 'flexibility' led many-perhaps most-students to expect that they would not have to attend classes. Students became disgruntled with the notion of class attendance, and great efforts were made to accommodate them: in 2000, for example, night classes with 
just two or three students were run in various courses. Since 2001 a different view has been taken. (Contemporary Studies Programme 2003:25)

Inexperienced students will behave rashly, make poor judgments and cut corners if such options are made available. Instead, they must be reminded that their words and ideas matter, and how-with effort, care and respect for knowledge-they can make a difference. Similarly to the experience in Queensland Australia, a sophomore at Duke University, Ryan Sparrow, justified the use of his ipod.

Sparrow explained one way he prepared for his presentation. "I downloaded the lectures from the [class Web site] and I put them on my ipod," he said. "One of them I listened to while I was at work at the Provost's office. I was upstairs in the attic doing some filing and I got to just listen to the lecture and take some notes." (The recording from Belkina's first lecture was particularly helpful for Sparrow, who had missed that class after staying up late to complete an engineering project.) (http:// cit.duke.edu/ideas/newprofiles/lucic.do)

Sonic materials can be written specifically for the ipod in the memo function. They can incorporate questions, diverse sounds and material written specifically for the ear. The ipod has great potential for teachers and students. But to simply record lectures, with or without copyright approval from the lecturer, is not a strong deployment of sonic media platforms.

The ipod offers remarkable potential for education. Yet a concern to address is how to transform an instrument of leisure into a vehicle for learning. Instead, the rush to i-lectures, without attention to theories of student motivation, has propelled into an imperative for the ipod. There are other ways to use the slim white case with wheel menu. The gleaming white platform for digital compression files is not either intrinsically helpful or damaging for education. However, with good curriculum, it can be an avenue and place for the presentation of teaching and learning materials. The ipod has the potential to create a higher quality web-cast of audio content than the i-lecture, written and recorded specifically for that purpose. No lecture rooms need to be wired. Copyright concerns are discussed and explored more overtly. Staff can—through the ipod's microphone attachment-record material of reasonable quality, appropriate for the web and the cohort of students, and is a polished presentation written for that purpose. But such a scheme would require investment in staff training, not technology.

Ryan Sparrow was part of Duke University's scheme in August 2003 to give twenty gigabyte ipods to first year students. They were preloaded with orientation materials in spoken and text form, along with information about Duke's academic environment, student life and activities. While the primary way the ipod was used by students was to download music, it was being used for course work, recording lectures and interviews, organizing image and text files, and also became a portable hard drive. Audio books, including language dictionaries, allow the development of sonic literacies and broaden the experience of education into diverse sites of life.

The desire to digitize, categorize and codify analogue, mixed media lectures into an inappropriate audio format discredits the complexity of sound and the resistive and plural energy of a lecture space. Sounds require precise mapping and shaping of differences. It is not an 'enhancement' to internet education. It must be used carefully because sonic media has some disadvantages. The speed of listening is slower than reading. While this reflexive pace is effective when presenting abstract ideas, the overall structure of material is more difficult to track. Long monologues and dense factual material from lectures are difficult to capture through sonic media. Meacham and Butler (1988) described sound as a "means of personalizing material, providing variety and interest, and presenting information whilst the eyes are occupied elsewhere, or merely resting" (p. 2). The most effective use of aural sources occurs when they are integrated with other media to motivate students and personalize the delivery of the instructor. The (only) reason why audio analogue cassettes were useful for distributing lectures is that they were practical and cheap. The best use of audio is when objectives are clearly stated and the form and content are related to the learning outcomes of the course.

A.W. Bates, in reviewing the successes of the Open University, has presented one of the most significant historical investigation of sound in teaching. He explored the significance of media selection in distance education, including the history of audio cassettes for Open University courses. He stated that,

Audio cassettes are low cost; all students already have facilities at home; they are easy for academics to produce, and cheap and simple to distribute; students find them convenient to use; and, when designed properly, they encourage student activity. (UK OU audio-cassettes are rarely lectures.) (Bates 1993:242)

There are lessons to be drawn from the Open University's use of audio cassettes. They were chosen because they 
were low cost, accessible, able to be produced by academics without intervention from others, and convenient to use. Significantly, in terms of educational design, lectures were inappropriate in developing effective sound-based OU educational strategies. While institutional use of technology aims to improve efficiency and productivity, teaching technologies must be influenced by other directives such as the student's home environment. Audio cassettes were cheap. Broadband, ipods and computers are not. Attention is also required on how particular courses and student cohorts require different media for distinct learning outcomes. Bates established a checklist of six criteria through which to assess educational technology:

- Cost

- $\quad$ Learning effectiveness

- $\quad$ Availability to students

- User friendliness

- Place in the organizational environment

- Recognition of international technological inequalities (Bates 1993: 243)

Instead of deploying such modes of assessment, funding is cut from 'conventional' teaching budgets to promote web-based resources, thereby reducing the options of staff in maintaining the current diversity of mixed media. The illegality of webcasting and podcasting (copyrighted) sounds means that audio and visual materials from film and popular music are removed from conventional—corporeal—lectures. The plurality and density of 'old' media such as film, photographs and television — and their attendant literacies_-is lost in a desire to render lectures uniform and legally downloadable.

The i-lecture - a platform developed by the University of Western Australia and being sold around the world-is an archetype of how and why web-based streaming of lectures is being deployed. I-lecture software digitally records a lecture and, through streaming, allows it to be heard via the World Wide Web. The system is automated, so that staff are not involved in — and implicitly cannot 'ruin'- the recording process. They simply switch on a microphone and recording commences, ceasing fifty minutes later. The media file is then transferred over the network from the lecture theater via the file transfer protocol (ftp). The recordings are compressed, uploaded and streamed to servers distributed over the network. Students then access these recordings. The reality is that-after eight years of webbased literacy and proliferation of hardware, software and wetware_-staff have not yet developed 'the content' (or literacy) necessary to run a 'virtual' university. At least with i-lectures, 'content' is made available, without staff input or-more troubling — without training and professional development of academics.

\section{I-ntellectual Property}

Before a student records a lecture onto an ipod or a lecturer flicks the switch on the lectern for an i-lecture, intellectual property concerns punctuate the space between the lips and the microphone. Alan Albright, specialist in intellectual property litigation in the United States, asked of students, "Do they have permission from the person who wrote the lecture? That would be a copyright concern" (Albright in Shreeve 2005:44). Yet, the copyright and intellectual property rights of staff have been ignored and perhaps violated. Such transgressions are systematic of an institution created around technological change, not teaching expertise.

Overwork and over management have sliced through the profession of teaching. There is an assumption that administration is facilitating teaching. Actually, the inverse is the case. Mechanisms for coping, rather than innovation, are the imperative. It has been fascinating in the last few years watching university administrators trying to force academics to 'get materials online' without cutting their workload to encourage research and professional development. Compliance has been enforced through top-down policies, yet resistance emerges at the grassroots. Experienced staff are retiring, switching to part-time or leaving the system. They are managing change by relocating to another job. The long term costs to the systematic and structural degradation of the institution are enormous. We will not know what is lost until it is gone.

Even more seriously, universities_-when managing the i-lecture project—have either overlooked or confused the issues of intellectual property rights and copyright. Teaching, and in particular lecturing, has not been configured as a scholarly act that creates and builds knowledge. While being guided by the same national law, different universities have assembled distinct rules and interpretations. For example, Macquarie University in Australia made the following 
claim on their website:

Staff engaged to teach can expect to have their voice captured, used and potentially reused to meet the needs of the university. (http://www.copyright.mq.edu.au/lecture/)

Macquarie has — without question or debate_claimed the intellectual property rights of academics over their own lectures. Simultaneously, they have also noted the copyright held by others in music and videos. They also confirm that "copyright is a type of personal property right that is founded on a person's creative work." (http://www.copyright. mq.edu.au/faq.html) By Macquarie University's definition, lectures are neither personal property nor creative work. The University of Western Australia, which developed the system, contradicts Macquarie's determination. Michael Neville and Michael Fardon cite Australian employment law, confirming that the works generated by an employee usually reside with the employer, but they also recognize that academic employment contracts differ from this determination. When the iLecture project was first undertaken at UWA, academic staff had all rights to their IP with the exception of digital works (e.g.: software) that remained with the university. A recent revision of regulations has seen the rights to recordings and papers being retained by the Academic with the University having a right to reuse the Intellectual Property. To address some teaching staff concerns that they would be made redundant by the recording process, the UWA iLectures team worked with teaching unit coordinators to get their view if recordings should be retained from year to year. To date this has been successful in keeping teaching staff involved in the process. Clear IP policies acceptable to teaching staff are critical to garnering their support for the lecture recording process. (http://ilectures.uwa.edu.au/misc/NevilleFardon_Educause_N48.pdf)

Significantly, the Law School at Melbourne University has not enforced or assumed the institution's intellectual property rights over i-lectures. Instead, the School confirms that "it is essential to note that iLecture is an opt-in capability. Only if an academic staff member chooses to have their class included, will it be recorded and made available on the web." (http://www.law.unimelb.edu.au/iss/informationsystems/services/ilecture/) Such a strategy smoothly detours a discussion of a lecturer's intellectual property rights and copyright.

Digitization raises these intellectual property rights issues because it is extremely simple to reproduce and distribute sounds and images. Such an ease in uploading, downloading, streaming and saving is not well managed within copyright law, which is based on the concept of a single identifiable author. In the United States, there is a tradition that the Faculty owns their own creative written works, with the exception of patents and inventions. With the commercialization of intellectual property online, this right may be challenged. The debate resonates provocatively with the copyright issues involved in the ownership of online course material. Without a clear and unambiguous contract, monitoring intellectual property rights remain a difficulty (Holmes 2000). By the Australian Copy Act of 1968, copyright material may be used without the owner's permission only if it is by 'fair dealing' (Australian Copyright Council 2003). The ambiguity of this phrase does not assist university administrators and academics in the process of knowledge ownership. In the United States however, intellectual property rights have assisted academics in asserting their ownership of teaching materials (Pietrykowski 2001).

Organizational conflict is a major and understated problem in our universities. Conflicts over processes and tasks_ _ or teaching loads_ - are symptoms of an organizational culture in disarray or discord. By continually stressing the new and the innovative, the intellectual capital that staff have built through years of experience is undermined. Validating technological change through economic savings or — frequently unsubstantiated — student interest will not encourage already overworked staff to work harder, particularly when their experience has been denied in the past. What makes i-lectures successful, or any other software application that facilitates the web-based audio streaming of lectures, is how it is justified, managed and valued in universities. Academic knowledge and teaching are not respected while issues of intellectual property rights and copyright law are either ignored or handled differently by distinct universities. Actually, copyright law applies to all recorded materials. Stunningly, Australian universities have assumed that academic staff will obtain — and pay for-the clearance of copyrighted materials, but that they will not be compensated for their own intellectual property being moved and traded through digital platforms. That is, staff pay for the right to use materials from which the university gains profit through the uploading of i-lectures and downloading onto ipods.

You are responsible for obtaining appropriate permission for all material delivered by the iLecture Recording System. This includes copyright clearance and/or payments for any material that you have requested to be recorded. (http://ilecture. unsw.edu.au/FREQUENTLY\%20ASKED\%20QUESTIONS.CFM?DC=5) 
This remarkable situation has not been challenged by staff or their unions. For academics working in mediarelated fields, this is an expensive disaster. Why should individual staff be responsible for funding material to improve the institutional quality of university teaching?

Copyright law is based on a single identifiable author. A lecturer is clearly the author of the material they deliver. In U.K. law — through the Copyright Designs and Patents Act 1988 - a low level of originality is required (Stokes 2004). A lecture would easily fall within this law. The only acknowledgement of this major issue, particularly when administered by managers demanding compliance, is that students will be unable to save and copy the whole recording of streamed i-lectures. The mistakes in interpreting the law are compounded through a miscomprehension of technology. Not only are there tools to rip streams, but the most basic of digital recorders like an ipod can create a good copy of streamed audio. The ipod can then be plugged into a USB slot to generate a wav file. This file can then be placed on the web, to be downloaded at will. Now, without handling the concerns with the i-lectures platform, there has been a fast movement to the ipod. Through this platform, there is no question that MP3 files can be copied. Because intellectual property rights were not addressed through i-lectures, this disregard continues to the next 'innovation.'

\title{
| Student Learning: New Ways to Miss the Point
}

\author{
Universities are in the information dissemination business and computers are changing the way they work.
} - M. Gordon Hunter and Peter Carr (2000:50)

Hunter and Carr's statement is punchy, provocation and enticing. It is also wrong. Universities develop new knowledge, not only reproduce it. University academics have functions and roles distinct from other teachers in the educational sector. They not only disseminate information, but are involved in the creation of knowledge through research. Too often these functions of academic life are partitioned. Instead, research and teaching conflate, dialogue and spark innovative theories. Such a misunderstanding of scholarly functions serves to devalue the multiple sites of academic's knowledge production, including lectures. If scholars simply reproduced the information of others, then issues of intellectual property rights and cultural value would not be as significant.

Perhaps the best explanation of how we reached this point in the ipodification of education is revealed by Rachel Johnson in her analysis of the contemporary university as a workplace (Johnson 2003:289-314). She demonstrates the consequences of senior manager-academics being removed from daily contact with students. Because of this displaced reality, university management makes many assumptions about students, such as the demand for flexibility. Concurrently_and conveniently_-'flexible learning' is a cheaper option than employing well-trained and credentialed scholars. International ranking systems, such as the Research Assessment Exercise in the United Kingdom or the Research Quality Framework in Australia, serves to increase the attention and value of research over teaching. Research is becoming a resource input for a university, whereas teaching is a cost. The result of this ideology is that academic staff are being asked to do more with less money, and are valued less for the work that they complete. This is not the time or environment to demand that staff lose intellectual property rights and 'fit in' with administrative directives.

The i-lecture is a symptom of a financially-starved university sector, employing overworked staff, enrolling under-inspired students and cutting costs in professional development. Instead of academics developing-with time, precision and consideration-materials that utilize the specific attributes of the web such as hypertext links, the i-lecture is a cheap, inappropriate, and low quality application for education. It confirms that the e-ducation revolution never arrived. The only managerial option was to upload already existing-analogue_-lectures, ignoring intellectual property rights, and hope no one would notice. By taking the creation, management and distribution of content out of the hands of academics, the language of teaching and learning changes. Suddenly "web content management" replaces well-theorized and delivered scholarship. Universities are making specific assumptions about students having home access to not only computers and ipods, but the literacy to manage the downloading and the management of sonic educational materials. Ironically, while forgetting about the classed and age-based inequalities manifested through the internet, i-lectures were justified by the University of Western Australia as providing an "equality of access, regional programs and expansion into international markets." (http://www.unsw.innovationxchange.com. au/page.print.html?article_id=00000000483) This 'equality argument' has been now lost, through the breaking of 
this link. The digital divide accurately shadows analogue inequalities (Kapitzke 2001). The assumption of Broadband availability, and even a reliable telephone system, cannot be made in rural and regional Australia.

Without a nod to, or recognition of, these concerns, a prototype for i-lectures is offered for public 'view.' http:// ilectures.uwa.edu.au/ilectures/ilectures.lasso?ut=726\&id $=33817$

The University of Western Australia, which developed i-lectures, presented this link as the best practice and exhibition of their product. The example presented is Paul Crompton's lecture on "Inflation." The expectations I brought to this review process before clicking open the sound file are important to recognize. I had predicted that the i-lecture presentation would be dry and poorly deploying sonic media and literacies, but technologically competent. I intended to evaluate the i-lecture through the use of voice, the mixed media deployment of PowerPoint slides, the use of the visualizer and consider how the aural delivery was paced and structured. This criteria of assessment was derailed in a remarkable way. The shock of my displaced expectations was stunning.

I accessed this site from a dial-up connection, rather than through the broadband connection at my university office. The sound dropped out through the streaming process. The lecture did not commence at the start of the session, but approximately 90 seconds into the recording. The 'visual component' was a graph which was drawn and augmented in scattered and irregular 'stream time,' not real time. The prototype-either implicitly or explicitly-did not present copyrighted material or address the consequences of doing so. The choice of lecture topic-inflationmeant that the difficulties in gaining permission for the use of film or television extracts were not hinted or suggested.

The great surprise through this process was the extraordinarily poor quality of the streamed recording and the lecture performance itself. I had assumed that-considering that this prototype was being used to sell the application - it would be a gleaming example of a fine speaker, a riveting topic and a seamless presentation of the streamed session. Instead, the lecture was poorly structured and not well-delivered. This example was used-I assume-because the lecturer deployed 'the visualizer.' Once more the hardware was prioritized over other wetware of form, voice and topic. The tool was used, but not well. It seems that within this model of educational discourse, the technology 'itself' is always enough, rather than evaluating the quality of the use. The hand movements around the graph were jilted and distracting. The viewer never saw the lecturer, the students or anything that actually moved. Beyond the visual realm, the sound quality was poor. Hundreds of sentences were distorted through the dial-up connection-the connection that most students use from home. The scroll bar also encourages bad behaviour. Students_-bored with the audio-only delivery_can scroll through the lecture without listening to it. Certainly this process is convenient, but it does not facilitate learning.

The silent issue of the i-lecture discourse as it moves into the ipodification of education is how easily the community of scholars and the excitement of learning have been traded for flexibility. Education is about creating relationships. There is an implicit—and occasionally explicit—realization that the i-lecture will lead to compromises and the university authorities are prepared to accept this. Until I opened up the streamed lecture, I was not aware of the scale of these compromises. The i-lecture may permit viewing of PowerPoint slides. It may permit some graphs to be viewed through the visualizer. The one attribute it does not permit is the clear and uninterrupted presentation of the human voice. The i-lecture can do a great many things, except present a lecture.

The accelerated realities of university education are taking hold. Students expect lectures to be made available for consumption. They claim — as our paying clients - that they have a right to demand service even if they are lazy, poorly-motivated, bored or skewed in their priorities. A student-with some horror-asked me before a first-year lecture in 2005, "But what happens if we miss your lecture and it is not available on i-lecture?" My reply was curt, but I think tethers to the core of our current problems in teaching and learning. I replied_-with a smile_-"if you make a decision to miss the lecture, then that is fine. But there are consequences for your actions." Confusion filled her face. Needless to say, the attendance at my lectures was high, excellent assignments were submitted and a fine cohort of students were produced who cared about the topics and each other. Without connecting student behavior and scholarly consequences, teaching and learning will not function. Education is not convenient. Learning is frequently not pleasant. Asking students who are enrolled in a university course to be on campus for 150 minutes in a week is not curtailing their life choices. The opportunities for avoidance that we have created will not help these students in the long term. Let me explain. I attended university during a kinder time for capitalism. There was still full-time and permanent work, universal health care coverage and a reasonably functional welfare state. Yet the education system in which I was enrolled was ruthless. If the assignment was late, then it would not be marked. I remember students on multiple occasions being expelled from tutorials for not completing the reading. We rarely saw our teachers outside of class time. We had to work it out for ourselves. It was an environment of fear: a fear of failure. At the very time that capitalism was benevolent, the university system was preparing us for the ruthless inequalities we would confront 
upon leaving the leafy campus.

Now that there are wars on terror, casualized workplaces, little union protection for workers and an economy based on credit card debt, universities are soft, kind and cuddly institutions, shielding our students from the dire scale of social injustice. At the very time that we mouth the rhetoric that universities prepare students for the workplace, we are actually masking the sickening inequalities, injustices and disrespect that is the marinade of contemporary life. Actually, if we failed more students, expelled them from classrooms for not doing the reading, and demanded their presence on time and on topic, then we would be preparing them for the workforce. When bosses expect i-work for their i-salary, then i-lectures on an ipod may have a place.

\section{References}

Australian Copyright Council. 2003. "Fair Dealing." Information Sheet G79. Sydney: ACC.

Barrell, Barnie. 2000. "Literacy Theory in the Age of the Internet." Interchange. 31:447-56.

Bates, A.W. 1993. “Technology for Distance Education: A 10 Year Perspective." Pp. 241-65 in Key Issues in Open Learning-A Reader, edited by A. Tait. Harlow: Longman.

Beard, Lawrence and Cynthia Harper. 2002. "Student Perceptions of Online Versus on Campus Instruction." Education. 122 658-63.

Brabazon, Tara. 2005. "From Eleanor Rigby to Nannanet: The Greying of the World Wide Web." First Monday 10. Retrieved February 4, 2006 (http://www.firstmonday.org/issues/ issue10_12/brabazon/index.html).

Bull, Michael and Les Back. 2004. The Auditory Culture Reader. Oxford: Berg.

Cixous, Helene. 1980. “The Laugh of the Medusa.” Pp. 245-67 in New French Feminisms, edited by E. Manks. Brighton: Harvester.

Contemporary Studies Program. 2003. Submission to Review. Brisbane: University of Queensland.

"Copyright for Staff." Retrieved July 31, 2004 (http://www. copyright.mq.edu.au/faq.html).

Crompton, Paul. N.d. "Inflation." Retrieved February 2, 2006 (http://ilectures.uwa.edu.au/ilectures/ilectures. lasso?ut=726\&id=33817).

Duncum, Paul. 2004. "Visual Culture Isn't Just Visual: Multiliteracy, Multimodality and Meaning." Studies in Art Education 45:252-64.

Green, Diana interviewed by Sophie Borland. 2005. "The Campus Question." The Independent. April 7, p. 5.

Hearn, James and Melissa Anderson. 2002. "Conflict in Academic Departments: An Analysis of Disputes over Faculty Promotion and Tenure." Research in Higher Education 43:509-29.

Holmes, Georgina et. al. 2000. "Who Owns Course Materials Prepared by a Teacher or Professor?: The Application of Copyright Law to Teaching Materials in the Internet Age." BYU Education \& Law Journal 165:1-29.

(http://cit.duke.edu/ideas/newprofiles/lucic.do). "Ipods Help Carry on Class Discussions.” Retrieved March 20, 2005.

(http://ilecture.unsw.edu.au/FREQUENTLY\%20ASKED\%20 QUESTIONS.CFM?DC=5). N.d. "I-lecture FAQ." Retrieved July 7, 2004.

(http://www.ccpr.murdoch.edu.au/opportunity/mp3.html). 2006. "MP3 technology_A New Wave in Learning." Retrieved January 28, 2006.

(http://www.copyright.mq.edu.au/lecture/). N.d. "Macquarie University Copyright Unit.” Retrieved July 31, 2004. (http://www.law.unimelb.edu.au/iss/informationsystems/ services/ilecture/). N.d. "Information Systems and Services." Retrieved July 31, 2004.

(http://www.murdoch.edu.au/teach/ilecture/usage.html). 2003. "I-lecture-How to Use I-Lecture." Retrieved July 31, 2005.

(http://www.unsw.innovationxchange.com.au/page.print.html?article_id $=00000000483) /, 2004$. "I-lectures-Enabling the Collection and Delivery of Digital Content on-Demand." Retrieved July 31, 2004.

Hunter, M. and P. Carr. 2000. "Technology in Distance Education: A Global Perspective to Alternative Delivery Mechanisms." Journal of Global Information Management April-June:50-55.

Johnson, Rachel. 2003. “Talking of Students: Tensions and Contradictions for the Manager-Academic and the University in Contemporary Higher Education." Higher Education 46:289-314.

Kapitzke, Cushia. 2001. "Information Literacy: The Changing Library." Journal of Adolescent and Adult Literacy 44: 450-56.

Meacham, E.D. and B. A. Butler. 1988. Audio Tapes for Distance Education. Riverina, Division of External Studies RiverinaMurray Institute of Higher Education.

“MP3 technology." 2005. The Australian. December 17:4.

Neville, M and M. Fardon. N.d. "Case Study: Stages in Establishing a Large Scale Streaming Media ImplementationAn Institutional Perspective." Retrieved August 1, 2004 (http://ilectures.uwa.edu.au/misc/NevilleFardon_Educause_ N48.pdf.).

Norquay, M. 1987. “Writing for the Ear.” Pp.1-11 in Listening to Learn, edited by L. Burge, M. Norquay and J. Roberts. Ontario: Ontario Institute for Studies in Education.

Pietrykowski, B. 2001. "Information Technology and Commercialization of Knowledge: Corporate Universities and Class Dynamics in an Era of Technological Restructuring." Journal of Economic Issues 35:294-307.

Plato. 1977. Phaedrus. Cambridge: Harvard University Press.

Rasdien, Peta. 2006. "Uni Students Sign Contract to Turn Up." The West Australian. February 4:58.

Robertson, John. 2003. "Stepping Out of the Box: Rethinking the Failure of ICT to Transform Schools." Journal of Educational Change 4:323-344.

Ross, J and R. Schultz. 2004. "Using the World Wide Web to Accommodate Diverse Learning Styles." College Teaching 47:10-23.

Sharp, Stephen and Simon Coleman. 2005. "Ratings in the Research Assessment Exercise 2001-the Patterns of University Status and Panel Membership." Higher Education Quarterly 59:153-72. 
Shreeve, J. 2005. "iListen and iLearn." The Independent. June 22: 44.

Simpson, Ronald. 1998. "Teaching as a Scholarly Activity." Innovative Higher Education 22:153-55.

Stearns, Peter. 1996. "Teaching and Learning in Lectures." Pp. XXX in History in Higher Education, edited by A. Booth and P. Hyland. Oxford: Blackwell.

Stokes, S. 2004. "Some Reflections on Art and Copyright." Electronic Journal of Intellectual Property Rights Retrieved August 14, 2004 (May: http://www.oirc.ox.ac.uk/EJWPO604. html).
Topping, Earle. 1987. "Voicing for the Ear." Pp. XXXX in Listening to Learning, edited by in L. Burge, M. Norquay and J. Roberts. Ontario: Ontario Institute for Studies in Education. Welsh, Irvine in Steve Redhead, 2000. Repetitive Beat Generation. Edinburgh: Rebel Inc.

Whitehead, N. [1932] 1942. The Aims of Education and Other Essays. London: Williams and Norgate. 